Recibido : 29/05/2015

Aceptado: 08/08/2015

Aragón en la Edad Media

26 (2015) 321-349

e-ISSN: 2387-1377

ISSN: 0213-2486

\title{
GEOGRAFÍA DE LA POBLACIÓN INFANZONA EN ARAGÓN (SS. XIII-XV)
}

\author{
GEOGRAPHY OF INFANZON POPULATION \\ IN ARAGON $\left(13^{T H}-15^{T H}\right.$ CENTURIES $)$
}

\author{
Guillermo Tomás FaCI \\ Universidad del País Vasco / UPV-EH*
}

\begin{abstract}
Resumen: Los infanzones o hidalgos del norte Aragón eran un grupo conformado mayoritariamente por campesinos que disfrutaban de una condición legal privilegiada. Debido a las evoluciones locales divergentes en la formación del colectivo durante los siglos XIII y XIV, no se repartían homogéneamente por todo el territorio, sino que se concentraban en determinados valles y comarcas del Pirineo y las Cinco Villas, y escaseaban en otras zonas. Este artículo pretende describir su distribución geográfica a partir de fuentes diversas y proponer explicaciones plausibles basadas en las dinámicas internas de las comunidades rurales.
\end{abstract}

Palabras clave: Infanzones, Hidalgos, Campesinos, Geografía. Aragón.

\begin{abstract}
In the North of Aragon, infanzones or hidalgos were mainly peasants who enjoyed a privileged legal condition. Due to diverging local evolutions in the constitution of this group during $13^{\text {th }}$ and $14^{\text {th }}$ centuries, they were not uniformly spread over the territory. Infanzones were scattered in a few valleys and regions of the Pyrenees and the Cinco Villas, and few of them lived somewhere else. This paper intends to describe their geographical distribution using various sources, and to suggest some plausible explanations based on internal dynamics of rural communities.
\end{abstract}

Keywords: Infanzones, Hidalgos, Peasants, Geographics, Aragon.

* Este trabajo se ha desarrollado gracias a un contrato de la Convocatoria de Contratación para la Especialización de Personal Investigador Doctor en la Universidad del País Vasco (UPV/EHU), correspondiente al año 2014, y se enmarca en el proyecto de investigación HAR2013-44093-P, De la lucha de bandos a la hidalguía universal. Transformaciones sociales, políticas e ideológicas en el País Vasco (siglos XIV-XVI), del Ministerio de Economía y Competitividad del Gobierno de España, y en los trabajos del Grupo Consolidado IT-600-13 del Gobierno Vasco. 
Los «infanzones» o «hidalgos» constituyen un grupo característico de la sociedad rural del norte de la Península Ibérica durante las épocas bajomedieval y moderna, que se concentraba en el litoral costero y regiones montañosas que se extienden desde Asturias hasta Aragón (García de Cortázar, 1988: 161165 y 244-247). Desde un punto de vista jurídico, se integraban en la nobleza y disfrutaban de un estatuto privilegiado que afectaba a la fiscalidad, la justicia y el honor. Sin embargo, si se atiende a su actividad económica, resulta difícil segregarlos del campesinado con el que convivían (ambos trabajaban la tierra, ejercían oficios impropios de la milicia, etc.), lo que los situaba en un horizonte social muy distinto del de otras personas (a veces también calificadas como «infanzones» o «hidalgos») que tenían formas de vida totalmente aristocrática. Siguiendo las palabras de José Ramón Díaz de Durana (2004), son los nobles «sin nombre y sin historia».

El origen de este peculiar grupo ha sido objeto de una considerable preocupación por parte de los historiadores, particularmente en las regiones donde estuvo más extendido, como las provincias vascas, Cantabria o Navarra (Díaz de Durana, 2004: 23-84). Gracias a ello, sabemos que sus raíces no se hunden en la noche de los tiempos, sino que radican en un conjunto de procesos comunes a buena parte del Occidente cristiano (la creación de categorías jurídicas para definir las realidades sociales, la diversificación económica dentro de la sociedad rural, la liberación de las servidumbres o la definición de las relaciones con el Estado), aunque los resultados en estas regiones peninsulares fueron excepcionales a nivel europeo.

Aunque es sabido que este fenómeno alcanzaba, hacia el este, el reino de Aragón, la atención que la historiografía sobre la hidalguía le ha prestado es sensiblemente menor que en Castilla. A ello ha ayudado que era una particularidad de algunas comarcas septentrionales, y que carece del peso en la percepción del pasado aragonés que ha tenido en las provincias cantábricas. La mayoría de los estudios existentes están anclados en la óptica de la genealogía y heráldica (adoleciendo de toda voluntad interpretativa), mientras que otros analizan a los infanzones exclusivamente desde la perspectiva de la aristocracia, dejando al margen a los campesinos privilegiados en que se centra este artículo. Sólo en los últimos años se ha empezado a abordar esta cuestión desde perspectivas propias de la historia social del mundo rural, gracias a historiadores como Juan José Larrea (2005), Carlos Laliena (2008; 2012) o Juan Abella (2006; 2012).

A pesar de los avances, los infanzones de Aragón siguen siendo un grupo mal conocido. Los Fueros y ordenamientos locales definen con precisión el 
marco legal, pero su realidad empírica (nivel económico, poder político, identidad colectiva, estrategias sociales, distribución geográfica ) permanece, en buena medida, en la penumbra. Y esto sucede a pesar de que la abundantísima documentación aragonesa de los siglos XIII y XIV convierte a este territorio en un laboratorio excepcional para indagar en cuestiones que resultan muy difíciles de analizar en Navarra o Castilla.

Este trabajo quiere trazar un panorama general de la población infanzona en Aragón entre los siglos XIII y XV. Para conseguirlo, se parte de dos ideas fundamentales: primero, que este grupo social no se distribuía homogéneamente por todo el territorio, sino que se concentraba en determinadas comarcas y pueblos del norte del reino (Abella y Sesma, 2004: 126-128), y segundo, que estas desigualdades territoriales no eran aleatorias ni irrelevantes, sino que se deben a la existencia de procesos divergentes en la organización de las sociedades locales. De acuerdo con ese planteamiento, este artículo tiene el objetivo de determinar la geografía de la población infanzona en Aragón, y proponer explicaciones plausibles a los desequilibrios que se aprecian.

Para dar respuesta a esas cuestiones, se ha recurrido a fuentes escritas con origen heterogéneo, que permiten observar la condición infanzona desde perspectivas tan diversas como la fiscalidad ordinaria del rey, los fogajes aprobados por las Cortes, los servicios armados, los reconocimientos individuales de este estatuto o las concesiones colectivas. Ninguna tiene carácter sistemático ni se concibió con la finalidad con que aquí se ha utilizado, pero de su combinación se pueden extraer datos fiables relativos a casi todo el territorio estudiado.

Antes de entrar en materia, se debe aclarar el léxico utilizado tanto en los documentos como en este artículo. En primer lugar, los vocablos «infanzón» e «hidalgo» eran sinónimos a todos los efectos, aunque el empleo de la segunda palabra en las fuentes aragonesas fue minoritario (pero creciente) durante el periodo bajomedieval (Lacarra, 1975); aquí se emplearán ambos términos de manera indistinta. En oposición a ellos, los campesinos que carecían de esa condición privilegiada eran calificados como «villanos», «pecheros», «hombres de signo servicio» $\mathrm{u}$ «hombres de condición».

\section{Las fuentes fiscales}

La extensión de la infanzonía a extensas capas sociales del campesinado en el norte de la Península Ibérica está relacionada, entre otras cosas, con la 
emergencia de la fiscalidad estatal durante los siglos XIII y XIV y con los intentos de muchos por minimizar su impacto sobre sus economías (Laliena, 2013: 466-472; García de Cortázar, 1988: 163-165). La documentación fiscal en la Corona de Aragón, abundante a partir de 1250, permite observar el fenómeno y acotarlo territorialmente a determinadas zonas. ${ }^{1}$

\section{Los inventarios o «cabreos» de rentas}

Una perspectiva bastante completa procede de los «cabreos» que se elaboraban periódicamente para conocer las rentas del rey en Aragón. Se conservan y han editado tres de estos informes: el primero fue preparado en 1294 por Ínigo López de Jasa, merino de Huesca, para reorganizar y consolidar los ingresos reales tras la primera Unión (1283-1289) (Bofarull, 1871: 203-312); el segundo se elaboró en 1315 por el funcionario Francisco Ferriol y comprendía los tres territorios de la Corona (Bofarull, 1871: 127-198); y el tercero se hizo en 1415 por mandato de las Cortes y de Fernando I para poner orden tras otra etapa de turbulencias, la que rodeó el Compromiso de Caspe (Vendrell, 1977).

Según el texto de 1294, en aquella fecha todas las poblaciones de realengo del norte de Aragón debían pagar pechas al rey, salvo las ciudades exentas de Huesca, Jaca y Barbastro. Sin embargo, en el área occidental esta renta había sido frecuentemente permutada por un «tributo» anual que cada familia pechera abonaba individualmente, por lo general de diferente importe según su capacidad económica, lo cual permitía amoldar la recaudación a la oscilante demografía de esas localidades fronterizas. Más concretamente, eso se atestigua en las Cinco Villas (Ejea, Sádaba, Sos, Luna, Biel, Ibardués y Longás) y la Canal de Berdún (Tiermas, Villarreal y Lorbés).

El informe denuncia la existencia de zonas en que no se podían cobrar las pechas por falta de contribuyentes. Así sucedía en muchas aldeas del entorno de Jaca (Gracionepel, Martillué, Navasilla, Jarlata, Sabiñánigo, Rapún, etc.), dos villas del Viejo Sobrarbe (Coscojuela de Sobrarbe y Olsón) y el valle de Puértolas. Todos estos casos tenían en común que desbandada de los pecheros (los peiteros s'ende son exidos) redundaba en el incremento de las heredades de infanzones: en el Sobrarbe se señala únicamente que las tierras que

1 A título comparativo, se han utilizado fuentes fiscales para establecer la geografía de la hidalguía en otros territorios próximos, como Navarra (Berthe, 1984: 82-92) y Castilla (Molinie-Bertrand, 1974). 
habían quedado incultas se habían arrendado a los segundos,,$^{2}$ pero en Jaca se acusó a ambas partes de una treta para esquivar el impuesto: algunos peyteros fizieron bendiciones de sus heredades a infançones, enpero los peyteros tienen et possiden las ditas heredades por manera de arrendamiento que les end an feito aquellos infançones por poco precio. En otras palabras, infanzones y labradores se habían aliado para que las exenciones de unos beneficiasen también a los otros.

El informe de 1315 es menos detallado y presenta un panorama bastante similar al anterior, aunque muestra algunas novedades en el área cincovillesa que evidencian el avance de las inmunidades fiscales. En primer lugar, se afirma que los hombres de Ejea eran «francos por privilegio de todas las cosas», lo cual se tradujo en la desaparición de la pecha que seguía apuntándose en 1294 , y se eximía de toda carga a los pobladores de El Real, un burgo recientemente impulsado por Jaime II entre las villas de Sos y Sangüesa, en plena frontera navarroaragonesa (Laliena, 2012: 428-431). También se indica que la permuta de la pecha colectiva por un tributo sobre cada casa se había extendido a pueblos como Uncastillo o Salvatierra de Escá, aunque en el primer caso la concesión real fue posteriormente rescindida. Por último, se expone en Lobera de Onsella una situación ya conocida: en el pueblo prácticamente no quedaban más que los infanzones a causa de la pobreza de los pecheros.

El último informe, correspondiente a 1415, no es tan amplio debido a las enormes enajenaciones del realengo durante el siglo XIV (Blanco, 1997), y muestra que la crisis había consolidado las situaciones descritas un siglo antes. Los burgos de las Cinco Villas reforzaron la exención de toda servidumbre real (pecha, cena, monedaje), caso de Ejea, Sádaba, Sos y Tiermas. Las pequeñas aldeas del entorno de Jaca que se mencionaron en 1294 quedaron en su mayor parte despobladas (cuanto menos, de pecheros) y las pechas que se les cobraban se perdieron definitivamente. Algo parecido sucedió en el valle de Puértolas: las antiguas rentas de los pecheros no se aluden, y el rey no cobraba más que arriendos por las heredades que pertenecieron a aquellos. Por último, en el valle de Aragüés del Puerto no se recibía nada, ya que todos los habitadores de los ditos lugares son infançones.

2 En el pueblo colindante de Buil sabemos, gracias a una investigación judicial de 1298, que se había producido un fenómeno similar de empobrecimiento y huida de los vecinos pecheros como consecuencia de la fiscalidad, que no afectó a los infanzones, por lo que cabe pensar que conllevó que éstos reforzasen su peso económico y demográfico (Tomás, 2014). 


\section{Los registros de la recaudación}

La colecta de impuestos también generó información que muestra, a través de la práctica, las dificultades que encontraron los recaudadores para reunir el dinero solicitado, especialmente acusadas en algunas zonas del tercio septentrional de Aragón debido a las franquicias colectivas y a las bolsas de población infanzona.

Manuel Sánchez ya señaló este hecho en un artículo que analizaba la contribución en los subsidios exigidos por Alfonso IV entre 1329 y 1335 para las campañas militares contra Granada (Sánchez, 1993). Numerosas localidades rechazaron pagar alegando franquicias (Salvatierra de Escá, Tiermas o el valle de Echo) o afirmándose infanzones (así sucedió en Santa María de La Peña, pequeño burgo del Prepirineo). Otros pueblos ofrecieron cantidades ínfimas que el rey prefirió rechazar para no sentar un precedente peligroso.

El repaso de los registros de otras peticiones ordinarias (pechas o cenas) o extraordinarias (subsidios, redenciones del ejército) corrobora este panorama poco halagüeño para el fisco. Por ejemplo, en 1293 Jaime II exigió a los concejos aragoneses importantes cantidades de moneda en concepto de redención del servicio en el ejército que asediaba al magnate Blasco de Alagón en el castillo de Alcaine (Laliena, 1996). Entre los papeles sueltos de este rey se conserva un cuadernillo que recoge la petición transmitida a cada lugar, además de gran número de anotaciones sobre las dificultades de los colectores, lo cual aporta un panorama de la fiscalidad en Aragón bastante completo. ${ }^{3}$ Las remisiones parciales del impuesto fueron generales en todo el reino, pero en ninguna zona hubo tantos problemas como en los distritos de Jaca, Ejea y Barbastro.

En algunos lugares, como Luna, Lobera de Onsella, la honor de San Juan de la Peña, el valle de Broto, Tierrantona, Castejón de Sobrarbe o Bestué, se consiguió una rebaja de dos tercios del importe, superior al tercio que se acostumbraba a perdonar en estos casos. En las villas de Canfranc, Berdún, Sádaba o Urriés, los valles de Ansó y Tena, el Sobrepuerto (la honor de Cortillas) o los dominios de Santa Cruz de la Serós, no se pagó nada en virtud de privilegios temporales de franquicia otorgados por la monarquía, en su mayoría debidos a las guerras de la década anterior. Por último, en Biescas, Murillo de Gállego, el Campo de Jaca, Sabiñánigo, Isuerre o Ejea se indica que los recau- 
dadores no consiguieron cobrar ni una moneda ni encontraron bienes embargables, debido a que estaban yermos de contribuyentes, pues no y estan sino infançons; en Ejea el recaudador se explayó un poco más al justificar su fracaso, y señaló que aquel loc es tot de infançons, et no y ha peyteros del senyor rey sino pocs, et son pobres et destruits, et no lur trobe res que penyorar.

Un registro muy diferente se elaboró en 1371, con motivo de la recaudación de un «maridaje» para la boda del futuro rey Juan I, que se refiere únicamente a las montañas del norte de Aragón, exceptuadas Ribagorza y las Cinco Villas. ${ }^{4}$ Los resultados evidencian que el funcionario exigió en casi todos los pueblos la cantidad fija de un florín de oro por fuego fiscal, lo que convierte a esta fuente en un incompleto fogaje de la región. De cada pagador se solía anotar la cantidad que abonaba, su localidad, su condición social (infanzón, hombre de condición, moro, judío, etc.) y, a veces, el número de casas por las que pagaba; por ejemplo: reebi de V infançons que ha en lo loch de Ossia, qui $\cdot$ ls atorgaren per la dita raho, Vflorins d'or. El carácter asistemático de la fuente dificulta su aprovechamiento estadístico, pero ofrece datos cualitativos de enorme valor para avanzar el propósito del trabajo.

Llama poderosamente la atención la desigualdad existente entre los valles. En Ansó, Echo o Borau no menciona infanzones, mientras que en Aragüés del Puerto, Sobrepuerto, Bielsa o Vio toda la población afirmaba serlo. El valle de Broto resulta paradigmático de esta tendencia a la homogeneidad legal de los habitantes de una misma comunidad, en un sentido u otro: entre las 85 casas de Torla no se cita a ningún infanzón, mientras que, entre las 60 de Linás de Broto, 10 de Oto o 5 de Labagüerre, no había quien no lo fuese; solamente la cabecera, la villa de Broto, presentaba una sociedad jurídicamente fragmentada (5 hidalgos frente a 25 hombres de condición). En los valles restantes (Tena, Puértolas o Gistau), los componentes de ambas categorías pagaron como un solo cuerpo, por lo que no sabemos la proporción de fuegos correspondiente a cada estatuto.

Más al sur y repartidas por la Canal de Berdún y las sierras del Prepirineo, aparece un mosaico de decenas de aldeas minúsculas (siempre por debajo de 10 casas pagadoras, en general bastantes menos) donde imperaban los infanzones, siendo especialmente abundantes en la cuenca media del Gállego, el curso bajo del río Ara y el entorno de Jaca. Por el contrario, en los burgos pe- 
queños y medianos de la región (Jaca, Aínsa, Canfranc, Salvatierra de Escá, Santa Cilia de Jaca o Villarreal de la Canal) no se distinguió entre ambas condiciones a la hora de pagar, bien porque no había infanzones, bien porque todos pagaron conjuntamente.

La información que el maridaje de 1371 aporta para los Somontanos es escasa, pudiéndose destacar sólo que las villas de Murillo de Gállego y Agüero eran mayoritariamente infanzonas, mientras que los pocos pueblos con datos fiables del entorno de Barbastro, como Pozán de Vero o Adahuesca, muestran lo contrario.

\section{El fogaje aragonés de 1405}

La siguiente fuente es propiamente un fogaje, esto es, un recuento de contribuyentes destinado a repartir un impuesto. Con seguridad, se trata del tipo documental más utilizado para el estudio de la demografía bajomedieval en toda la Corona de Aragón, a pesar de sus problemas metodológicos. Más concretamente, se va a analizar el que se elaboró en 1405 con el objetivo de recaudar un subsidio concedido por las Cortes de Aragón a Martín I, que fue editado y estudiado por Juan Abella y Ángel Sesma (Abella, 2008; Abella y Sesma, 2004). No se ha preservado el listado nominal de las unidades fiscales de cada pueblo (sin duda, existió pero se ha perdido), sino el registro de la gestión del impuesto, con las órdenes de pago y los recibos del cobro de la cuantía asignada a cada localidad, que dependía del número de fuegos, siempre especificados. Se trata del fogaje más antiguo con datos de la mayor parte del territorio, y el único que discrimina a infanzones respecto a hombres de condición.

A pesar de la calidad de la fuente, se deben advertir sus limitaciones (Sesma, 2004). Ante todo, no incluye todas las localidades del reino: las que se integraban en un mismo señorío laico o eclesiástico eran frecuentemente estimadas de forma unitaria; otras se omitieron sin motivo aparente (no pagaron el impuesto, no se registró o se han perdido las páginas correspondientes). Una variante del anterior problema son los pueblos en que sólo queda el testimonio de los infanzones o de quienes no lo eran, o en los que ambos se contabilizaron juntos, de manera que no podemos conocer la proporción. ${ }^{5}$ Además,

Es el caso de Sos, en que sólo se cita a hombres llanos y judíos, a pesar de que consta que existían unas 10 familias con esa condición (Abella, 2012: 9-10). De forma parecida, varios pueblos del Somontano de Barbastro sólo figuran en un resumen del número de hidalgos, omitiéndose el resto, de modo que una villa como Selgua, que sumaba 43 fuegos en 1495, en 1405 no se registraron más que 5 infanzones. 
hay que tener siempre presentes las dificultades de definir la célula contribuyente $\mathrm{o}$ «fuego», pues era habitual que, debajo de ella, existiese una población flotante de criados, jornaleros, hijos segundones, etc., especialmente en los medios sociales donde la casa indivisa era hegemónica (Tomás, 2010).

Antes de analizar los resultados, se debe apuntar que el condado de Ribagorza era una inmensa jurisdicción separada, que está deficientemente representada en 1405. En consecuencia, sus datos se han completado con un fogaje elaborado por orden del conde en 1427, para estimar el número de casas contribuyentes sin un objetivo fiscal inmediato.$^{6}$ Los datos resultantes se han plasmado cartográficamente en el mapa 1 .

Una vez hechas todas las prevenciones anteriores, que obligan a ser prudentes a la hora de dar por buenas las cifras exactas de pueblos concretos, sî que se puede afirmar que el fogaje proporciona un panorama impresionista bastante fiable de la distribución de los infanzones en el tercio septentrional de Aragón.

Si atendemos, en primer lugar, a la escala comarcal, se observan abismales diferencias dentro del área analizada: ${ }^{7}$ las Cinco Villas y Sobrarbe son, con un $45 \%$ y $41 \%$ respectivamente, los territorios con mayor proporción de fuegos infanzones, una cifra que disminuye hasta el 26\% en el Alto Gállego y el 17\% en Jacetania. Muy por debajo, se encuentran los somontanos de Huesca y Barbastro (8-9\%), Ribagorza (menos del 7\%) y La Litera, que apenas alcanza el $4 \%$. La primera conclusión clara es que la proximidad de Cataluña se traduce en los menores de porcentajes, fenómeno vinculado a la inexistencia de la categoría legal en el Principado. En el resto del territorio, destaca el contraste entre el extremo occidental (Cinco Villas y Jacetania), donde los hidalgos se agrupaban en los somontanos y escaseaban en las montañas, frente a Sobrarbe y su piedemonte, donde esa distribución se invertía.

Por último, en casos como Nocito los labradores dependían del señorío de un caballero y, por ello, contribuían lo mismo que sus vecinos infanzones, de modo que el documento aclara que en sus 34 fuegos estaban todos incluidos.

6 Archivo de la Catedral de Lérida, cajón 59/2 (P1-M3-P1-C04), «Libro Archiu de Ribagorça», ff. 68r$131 \mathrm{r}$.

7 Para establecer esas proporciones, se han regularizado los límites comarcales para ajustarlos a accidentes geográficos: de este modo, las Cinco Villas incluyen todo el espacio situado al oeste de los ríos Gállego y Asabón, y al sur del Aragón; la Hoya de Huesca la zona comprendida entre el Gállego y el Alcanadre; el Somontano de Barbastro desde el Alcanadre hasta el Cinca; y La Litera desde el Cinca hasta la frontera catalana. 
Pasando a la escala local, los altos valles del Pirineo muestran en 1405 un comportamiento bastante similar al que se describía a partir del maridaje de 1371. En Ansó y Echo no vivían prácticamente infanzones (sólo había unos pocos en el segundo valle, todos agrupados en la misma aldea, Biesa, hoy desaparecida). En el extremo opuesto, se encuentran los valles donde la mayoría de familias lo eran, como en Aragüés del Puerto (contiguo a los anteriores, con un $73 \%$ de fuegos hidalgos) o Garcipollera (79\%), ambos en Jacetania, o en los sobrarbeses de Bielsa (81\%), Puértolas (90\%) o Vio (100\%). La peculiar situación de Broto en 1371, donde según el lugar imperaban los infanzones o los pecheros, se confirma en 1405, y se atestigua asimismo en Gistau: en Sin, Señés y Serveto todos eran hidalgos, en San Juan de Plan todos de condición, y los pueblos de Plan y Gistaín estaban divididos (aunque había más de los primeros). En los valles restantes (Aísa, Tena o Benasque) los infanzones suponían entre el 10 y el $30 \%$ de los fuegos en casi todos los pueblos; a diferencia de los casos anteriores, esta situación facilitaba la asociación del estatuto privilegiado a una posición dominante en la localidad.

Más al sur las divergencias territoriales se mantienen, aunque tienen otro carácter, pues afectan sobre todo a las localidades más pobladas. En casi todas las ciudades y burgos rurales la población infanzona era minoritaria (14\% en Jaca, $8 \%$ en Huesca, $7 \%$ en Pertusa, $5 \%$ en Berbegal, $4 \%$ en Tamarite, $2 \%$ en Monzón), pero esta situación cambia drásticamente en las Cinco Villas, donde la mayoría de la población urbana o semiurbana lo era (100\% en Luesia, Orés o El Frago, 81\% en Ejea - todos menos los judíos - o 74\% en Murillo de Gállego). El carácter colectivo que se atribuía a la condición hidalga en las comarcas colindantes con Navarra es aún más evidente en Salvatierra de Escá o Villarreal de la Canal: ambos vecindarios exigieron pagar con el estamento de los caballeros como los de Ejea, pero no se les permitió y pasaron en bloque a las «universidades»; aunque se rechazase su petición, no hay duda de que en las dos comunidades existía la idea de que disfrutaban de un estatuto noble. Ante estos datos, parece claro que ser infanzón (por poner dos ejemplos) en Luesia y serlo Berbegal tenía un significado social diametralmente opuesto.

Por último, el mosaico de pequeñas aldeas que cubre las Sierras Exteriores, que en 1371 se presentaba como un área predominantemente infanzona, aparece en 1405 mucho mejor definida, lo que corrobora con matices la anterior percepción y muestra algunas diferencias regionales interesantes. Los dominios monásticos de San Juan de la Peña, Montearagón, Santa Cruz de la Serós o San Victorián, así como el entorno rural de Jaca (del que ya se habló más 
arriba), tenían una mayoría de fuegos hidalgos. Por el contrario, en la Guarguera, la Tierra de Biescas o La Fueva predominaban los hombres de condición y los vasallos de señores laicos.

\section{Los servicios militares durante la Guerra de los Dos Pedros}

La última fuente no es propiamente fiscal, sino que se refiere a un servicio militar que buen número de infanzones realizaron en 1357, en el marco de la Guerra de los Dos Pedros. A mitad de febrero de ese año, ante el asedio castellano sobre la ciudad de Tarazona, Pedro IV convocó a todos sus vasallos aragoneses, y senyaladament cavalleros, scuderos e infançones, para que el 8 de marzo se presentasen en Zaragoza para la defensa del reino, tal como era su obligación (Lafuente, 2014: 76-84); el monarca tomó especial interés en que los sobrejunteros de Huesca y Jaca se encargasen del cumplimiento de la convocatoria en el área pirenaica. El 4 de abril de 1357, el rey licenció a 306 infanzones de la mitad septentrional de Aragón, que eran probablemente la mayoría de las personas con esa condición que habían respondido al llamamiento, un listado que se puede completar con otros 6 que recibieron la misma concesión dos días después, y 29 más que lo hicieron el 21 del mismo mes (Falcón, 2008: 135-138). ${ }^{8}$ Aparentemente, todos sirvieron en calidad de peones, lo que confirma que carecían de caballo y de experiencia bélica.

Los 341 nombres no son, ni mucho menos, un listado completo de los infanzones aragoneses: muchos pueblos debieron ignorar el llamamiento (sobre todo, los correspondientes al señorío laico), los reclutamientos no superaban la proporción de un hombre cada cuatro casas, y, probablemente, ni siquiera estén todos los que acudieron en aquella ocasión (las actas de su licenciamiento están dispersas por los registros de la cancillería, y podría haber más). Ahora bien, la nómina de personas que respondieron a un llamamiento destinado a todo el grupo social resulta útil para ver, en líneas generales, su procedencia geográfica. Como se va a comprobar, los datos concuerdan con lo observado hasta aquí.

Las ciudades de Zaragoza, Huesca y Barbastro aportaron 82 hombres, otros 20 venían de localidades de Monegros o de las riberas del Ebro, 55 de

8 El documento publicado por Isabel Falcón se ha completado con varios licenciamientos: ACA, RC, reg. 1152, ff. 196v-197r; reg. 1381, ff. 21v y 23r. Agradezco a Mario Lafuente que me haya proporcionado estas referencias documentales. 
los somontanos (desde la frontera navarra hasta la catalana) y los 181 restantes de los Pirineos; de tres no conocemos el origen. En una escala comarcal, el contingente más abundante eran 97 que procedían de Sobrarbe, seguido de 52 que lo hacían del Alto Gállego; cabe aclarar que las Cinco Villas y Ribagorza quedaron al margen del llamamiento. Descendiendo al nivel local, los grupos más numerosos venían de altos valles como Broto (32), Tena (29), Gistau (13), Araguiés del Puerto (12) o Puértolas (7). Hacia el sur, se distribuían por el mosaico de pequeñas aldeas prepirenaicas, agrupándose en el entorno inmediato de Jaca (Caniás, Baraguás, Orante, Navasa, Áscara o Lastiesas sumaban una quincena), la cuenca media del Gállego (22 entre el valle de Basa, la honor de Serrablo y el caserío de Orna de Gállego) y el viejo Sobrarbe (Buil, Olsón, Guaso y Monclús sumaban 23). Por último, en las faldas de la cordillera destacaban los 12 hidalgos de Biel y 10 de Torres de Montes (un pequeño pueblo cercano a Huesca), pero en general su número era muy bajo en relación con la demografía y extensión.

Aunque los datos hay que tomarlos con precaución, permiten extraer algunas conclusiones generales. En primer lugar, confirman que la mayoría de los infanzones que respondieron a la convocatoria eran montañeses, y que su número se reduce conforme se desciende hacia el río Ebro, donde se agrupan en las ciudades. Segundo, es evidente la concentración en los valles del Pirineo central (desde Tena hasta Gistau), así como en el de Aragüés del Puerto, que vuelve a presentarse como el principal reducto infanzón en Jacetania. Por último, se intuye que en el Prepirineo se agrupaban en tres zonas concretas (entorno de Jaca, curso medio del Gállego y Viejo Sobrarbe) caracterizadas por el poblamiento aldeano o disperso.

\section{El reconocimiento de la infanzonía}

Para que una persona disfrutase de las ventajas inherentes a la infanzonía era necesario, ante todo, que las autoridades estatales, señoriales o locales le admitiesen como tal. De acuerdo con la legislación aragonesa, se trataba de una condición estrictamente familiar, basada en la pertenencia por vía paterna a un linaje que «poseía» esos privilegios. Los fueros aprobados en las Cortes de Aragón de 1247, 1265 y 1300 definieron progresivamente el procedimiento que un presunto infanzón debía seguir para que las instituciones reconociesen la hidalguía de su estirpe (Laliena, 2008; Falcón, 2008: 43-62). 
Según quedó establecido en 1300, el solicitante debía superar una causa ante el Justicia de Aragón con el fin de demostrar mediante testigos que cumplía una serie de requisitos: que nunca había entregado cargas que denotasen servidumbre, que existía una «fama pública» acorde con la petición, que podía mostrar el «casal» del que provenía su nobleza, que había dos caballeros dispuestos a jurar a favor de él, etc. En caso de que la investigación le fuese favorable, el Justicia lo notificaba a la corte real, donde se despachaba la «salva de infanzonía», esto es, el privilegio real que corroboraba su condición.

Este mecanismo judicial ha dejado un importante rastro documental en el Archivo de la Corona de Aragón: por una parte, se conservan unos 300 procesos de infanzonía del siglo XIV, aunque la mayoría no se puede consultar (Conde, 1999); por otra, todas las salvas expedidas eran anotadas sucintamente en los registros de la Real Cancillería (se anotaba el nombre del beneficiario, el pueblo donde habitaba y el casal del que venía su linaje). La historiadora Isabel Falcón ha desarrollado un vasto trabajo para recopilar esas salvas registradas, el cual ha resultado en una nómina de dos millares de personas que demostraron su condición privilegiada en los siglos XIII y XIV (Falcón, 2003). Aunque está lejos de ser una lista completa de las infanzonías salidas de la Real Cancillería, ${ }^{9}$ se trata de una muestra amplia y representativa que aporta información fiable y precisa acerca de la geografía de la población hidalga en Aragón.

El casal del que provenía la condición privilegiada del beneficiario se indicó en cerca de 900 ocasiones, y en 862 de ellas ha sido posible situarlo geográficamente (mapa 2). Se repartían por 350 localidades distintas del cuadrante nororiental de la Península Ibérica y sur de Francia. De ellos, 63 casales estaban fuera de Aragón (preferentemente en Navarra, donde había 51, en contraste con 3 en Cataluña o 6 en Castilla), y 799 dentro de sus fronteras: 38 al sur del río Ebro y 761 al norte. Cabe aclarar que si, en lugar del casal, se toma como referencia el pueblo donde residía el solicitante, el peso de la mi-

9 La compilación de Isabel Falcón se centra en las salvas anotadas en los folios iniciales o finales de los registros, pero apenas profundiza en las concesiones insertas en su interior. Además, muchos documentos son redundantes, pues suele incluir tanto la comisión real al Justicia de Aragón para que se investigue la infanzonía, como la sentencia, ambas sobre la misma persona. A título de ejemplo, en una conocida carta a Pedro IV de marzo de 1344 (Laliena, 2008: 27-28), se denunciaba que en los dos meses anteriores se habían pedido 120 salvas, pero Falcón no recoge más que 4; sin embargo, revisando los registros de esas fechas se encuentran muchísimas más: 21 que la autora data erróneamente en 1343, 49 de vecinos de Biel (ACA, RC, reg. 626, ff. 64v-65r), etc., lo que nos acerca a la cifra de la carta. 
tad meridional del reino se cuadriplica (173 al sur del Ebro, y 697 al norte). Se desprende de ello que la infanzonía era un fenómeno casi exclusivo de la zona norteña, y que desde allí se había extendido hacia el sur a causa de los movimientos emigratorios; por ejemplo, de los 68 solicitantes que residían en la ciudad de Zaragoza, 53 afirmaban descender de un casal del Pirineo aragonés o las Cinco Villas, y sólo 4 de otros puntos del reino.

Dentro de esa mitad septentrional de Aragón, se observa una distribución comarcal irregular. Las comarcas de Cinco Villas y Sobrarbe, con 197 y 165, mostraban las mayores densidades de casales, seguidas por Alto Gállego (114), Jacetania (107) y la Hoya de Huesca (83); su número se reducía drásticamente en Ribagorza (39) y el Somontano de Barbastro (33), y llegaba a ser prácticamente insignificante en el resto del territorio. No es prudente extraer conclusiones cuantitativas de esos datos (al fin y al cabo, el peso demográfico de cada territorio no era igual), pero permiten intuir un panorama marcado por la concentración de los casales en el Pirineo (excepto en Ribagorza) y en las Cinco Villas, es decir, se repite el patrón observado a partir de las fuentes fiscales.

Si pasamos a la escala local, llama la atención la existencia de pueblos donde se concentraba gran número de personas que querían ver reconocida su infanzonía. Para observar este hecho, resulta más útil fijarse en el pueblo en que residían los solicitantes, que en el casal del que descendían. Así, en 1263 Jaime I concedió la salva a favor de casi 350 familias residentes en Luna (el documento afirma que no había entre ellos hijos ni nietos de caballeros, lo cual confirma una extracción social bastante humilde); en 1264 a un centenar de Luesia, tras una investigación encargada por el monarca a una comisión de caballeros, hidalgos y labradores; ${ }^{10}$ en 1298 se otorgó a 51 de Biel, de los que 40 tenían el casal en este pueblo y 11 provenían de otros próximos; y en 1307 Jaime II lo otorgó a 50 individuos que se instalaron en El Real.

A raíz de las Cortes de 1300 el procedimiento legal para obtener la salva se endureció; tal vez, la desaparición de las concesiones masivas como las anteriores está relacionada con ello. Ahora bien, eso no impedía que, en un mismo día, todos o la mayoría de los vecinos de un mismo pueblo pidiesen salvar su infanzonía, tras lo cual se realizaba un proceso separado para cada solicitante, aunque el resultado solía ser similar para todos. Los casos se concentran cronológicamente en la primera mitad del siglo XIV y geográficamente en ciertas 
áreas del Pirineo aragonés: las sierras prepirenaicas del valle medio del Gállego y el norte de las Cinco Villas (101 solicitantes de Murillo de Gállego en 1325, 37 de Larués en 1323, 15 de Yeste en 1325, 15 en Riglos y Marcuello en 1331, 11 de Ruesta en 1302), los valles de Sobrarbe (13 solicitantes de Buesa en 1306, 6 de San Juan de Plan en 1316, 31 del valle de Gistau en 1326) y lugares puntuales de otras zonas ( 8 del valle de Aísa en 1302, 14 de Novales en 1315, 8 de Azlor en 1322). En otros lugares, las peticiones no se agrupan en una fecha, sino que las salvas se repartieron a lo largo de todo el Trescientos, sumando 20 en el valle de Puértolas, 16 en Orés, 14 en Aragüés del Puerto, 10 en Linás de Broto, 8 en Gistaín, etc.

No se puede olvidar que estas cifras son una mínima parte de las salvas otorgadas. Además, cabe suponer que las solicitudes se realizaban en aquellos casos en que la condición privilegiada causaba controversia, lo que deja en la sombra muchos pueblos en que eso no sucedía. Así las cosas, no parece exagerada la advertencia del consejero real Blasco de Aísa en 1344 de que, si no se ponía remedio, quantos hommes ha en los lugares de las montanyas de Aragon se faran infanzones (Laliena, 2008: 27-28).

\section{Los privilegios de infanzonía colectiva}

Aunque los Fueros de Aragón no contemplaban esta opción, algunos pueblos y valles del norte del reino recibieron privilegios reales o señoriales por los que se otorgaba la condición infanzona a todos sus vecinos, con independencia del linaje.

Las instituciones y juristas del reino fueron reacios a dar validez a esas concesiones colectivas, una actitud que se resume en la respuesta que las Cortes dieron a los procuradores de Ejea y Sádaba, ante su petición de integrarse en el estamento de la baja nobleza: los qui non son infançones de linage, sino por el privilegio o privilegios de las ditas villas ... verdaderament no son infançones de linage (Laliena, Iranzo y Martínez, 2008: 356-357). ${ }^{11}$ Los representantes de esas dos localidades (además de los de Tauste, Sos y Uncastillo) lograron la reivindicación, pero la victoria nunca pasó de un plano simbólico; por ejemplo, sólo los pocos infanzones de linaje podían sentarse en las Cortes

11 Los tratadistas aragoneses de época moderna profundizaron en la crítica a esos privilegios, con reflexiones como: «estos hijosdalgo no gozan de todos aquellos privilegios que a los verdaderamente infanzones les pertenecen» (Montemayor, 1665: 200-201). 
entre los caballeros para actuar en nombre del pueblo, y no el grueso del vecindario. Un indicio más contundente de su limitado valor es que, en los cientos de pleitos de hidalguía que se desarrollaron en los tribunales del reino entre los siglos XVI y XVIII, los únicos ennoblecimientos colectivos tomados en consideración fueron los que beneficiaban a las provincias de Vizcaya y Guipúzcoa y a ciertos valles navarros (Baztán, Salazar o Roncal). ${ }^{12}$

Una fuente objetiva para delimitar el alcance geográfico de la hidalguía colectiva son los padrones del siglo XVIII. ${ }^{13}$ Algunos ayuntamientos declararon que, aparte de los infanzones de linaje (los únicos que interesaban a las autoridades borbónicas), todos sus vecinos disfrutaban de esa condición en virtud de algún privilegio antiguo. Los casos se agrupan en dos regiones: las Cinco Villas y pueblos colindantes de Jacetania (Tauste, Ejea, Sos, Undués de Lerda, Tiermas y Berdún) y Sobrarbe (los valles de Vio, Puértolas y Bielsa, y las aldeas de Sin, Saravillo, Serveto, Muro de Bellós, Puyarruego y Coscojuela de Sobrarbe). Seguramente, no se trata de una lista completa, pero los indicios medievales se ajustan más o menos a esa corta nómina (mapa 2).

Se pueden distinguir dos caminos de acceso a la hidalguía colectiva en Aragón: en unos casos, era la conclusión de un largo proceso de liberación de la fiscalidad real y otras cargas por parte de concejos enteros; en otros, culminaba el reconocimiento individual de la nobleza a todos o la mayoría de los habitantes de una comunidad. El primero se detecta preferentemente en las Cinco Villas, y el segundo en Sobrarbe.

Las cartas de población y privilegios de franquicia otorgados a buen número de poblaciones entre los siglos XI y XIII recogían la concesión de derechos y exenciones propios de infanzones, con la finalidad de confirmar la liberación de cualquier tipo servidumbre (Laliena, 2012: 111-119). Sin embargo, esto no se tradujo (ni entonces ni posteriormente) en que se les reconociese realmente esa condición, con la excepción de Ejea de los Caballeros y los pueblos que se gobernaban por sus fueros (Lapeña y Agudo, 2003). La concesión original de Alfonso I en 1110 buscaba asentar una importante base de caballeros villanos, igual que se hizo en muchos pueblos del sur del reino,

12 Este extremo se comprueba insistentemente en los millares de procesos de infanzonía conservados que se desarrollaron ante el Justicia de Aragón, Real Audiencia o Diputación del Reino, que han sido recientemente catalogados de forma exhaustiva (Pardo de Vera, 2012 y 2013).

13 Se han consultado los correspondientes a los corregimientos borbónicos de Barbastro, Benabarre, Cinco Villas y Jaca, elaborados en 1733 y 1787 (Archivo Histórico Provincial de Zaragoza, Real Audiencia, cajas 1.866 a 1.871). 
pero, en su desarrollo posterior, esto se interpretó en términos de infanzonía, como se intuye ya hacia 1200, cuando se concedió esa norma a Tiermas y Salvatierra de Escá (Lapeña y Agudo, 2003: 152-167) ${ }^{14}$, y, ya sin ningún resquicio de duda, cuando se otorgó en 1408 a Oto (aldea del valle de Broto) o en 1458 a Sos (Abella, 2012).

Fuera del ámbito cincovillés, las concesiones se agrupan en el norte de Sobrarbe (López, 2006: 109). El caso más conocido es el valle de Vio: en 1278 el noble Corbarán de Aunes dio por buena la infanzonía de todos sus habitantes al comprometerse a no investigarla ni recurrirla ante ninguna instancia judicial, lo que parece más bien un pacto de silencio ante la incertidumbre que suscitaba su condición privilegiada. ${ }^{15}$ En 1462 Juan II confirmó el documento, que no se copió, sino que se resumió de tal manera que borraba cualquier atisbo de duda (per quodquidem privilegium habitatores vallis predicte declarantur fore infançones et hermunnos, ipsamque vallem infançonam seu infançonie privilegio gaudere). ${ }^{16}$ En 1360 , tras un proceso judicial que no se ha preservado, Pedro IV otorgó ese privilegio a favor de las aldeas de Sin, Muro de Bellós y Coscojuela de Sobrarbe. ${ }^{17}$ El citado lugar de Oto ${ }^{18}$ y el valle de Bielsa consiguieron lo mismo en 1408 y 1445, respectivamente, después de que sus vecinos comprasen los señoríos para anexionarlos al realengo (Bielza et alii, 1988: 215-221). Por último, los valles de Gistau y Puértolas poseían firmas de infanzonía otorgadas por el Justicia de Aragón a finales del siglo XV y comienzos del XVI.

Resta solamente por citar el caso de Santa María de La Peña, un burgo rural creado a finales del siglo XIII por el magnate Rodrigo Jiménez de Luna dentro

14 Que el significado que se daba al Fuero de Ejea iba más allá de su propio contenido, se observa, por ejemplo, en la confirmación de los privilegios de Tiermas en 1391 (ACA, RC, reg. 1900, ff. 65v-68r): allí se explica que los vecinos afirmaban estar exentos de toda forma de hueste en virtud de esa ley, pero que eso no aparecía en ningún epígrafe, así que la franquicia se puso por escrito para evitar dudas.

15 ACA, Consejo de Aragón, reg. 40, ff. 54v-71v.

16 Fondo Documental Histórico de las Cortes de Aragón, D56.

17 ACA, RC, reg. 904, ff. 82v-84r. Las tres aldeas beneficiadas del privilegio de 1360 estaban bastante alejadas entre sí y carecían de vínculos señoriales, por lo que el hecho de que se extendiese un privilegio conjunto parece estar relacionado exclusivamente con el hecho de las tres compartiesen la circunstancia de estar pobladas exclusivamente por infanzones.

18 ACA, RC, reg. 2205, ff. 135v-138r. El privilegio de Oto muestra claramente este camino - sobrarbés - hacia la infanzonía universal. A la altura de 1408 todas las familias eran ya hidalgas, al haberse extinguido las casas de «hombres de servicio». El texto explica la aparente contradicción de otorgar el Fuero de Ejea a quien ya tenía esos privilegios por linaje: así se pretendía asegurar que, si una familia de origen pechero se instalaba en el pueblo, se preservase la nobleza e inmunidad colectivas. 
del área de influencia de San Juan de la Peña (Lourie, 1996: 204-206; Laliena, 2012: 433-434). No se ha conservado la carta de población, pero sí varias referencias a la concesión de la infanzonía a todos los pobladores que se instalasen allí, que posteriormente fue ratificada por la monarquía. ${ }^{19}$

\section{Síntesis e interpretación de una geografía compleja}

Cada una de las fuentes documentales plantea diferentes problemas metodológicos para el objetivo concreto de este artículo, pero su combinación permite establecer con bastante precisión y certidumbre la distribución geográfica de los infanzones aragoneses, y además de aportar pistas sobre las diferencias en su nivel económico o en el origen de su condición.

Los beneficiarios de ese estatuto jurídico se concentraban en el tercio septentrional de Aragón, y más concretamente en el Pirineo (salvo Ribagorza), sus somontanos y las Cinco Villas. Fuera de ese territorio, son escasos, constituían un grupo minoritario dentro de cada pueblo, tenían un indudable sabor aristocrático (estaban vinculados a la alta nobleza, se intitulaban «caballeros» o «escuderos», etc.) (Lafuente y Abella, 2013) y, con frecuencia, justificaban su privilegio alegando un origen alóctono (pirenaico o navarro). A continuación se resume el reparto de los hidalgos en el norte del reino, abordando de manera separada tres grandes áreas geográficas en que los estatutos jurídicos adoptaban formas diferentes: las Cinco Villas, el Prepirineo y los valles.

\section{La hidalguía colectiva de las Cinco Villas}

Las Cinco Villas son la comarca aragonesa donde, según las fuentes fiscales, la población infanzona era más numerosa (Abella y Sesma, 2004: 126127), pero el hecho de que estas cifras no tengan un correlato en el número de salvas pone en alerta sobre el carácter de estos hidalgos. Las villas de Ejea, Tauste, Sádaba o Sos se libraron progresivamente de la mayor parte de las obligaciones fiscales con la monarquía (incluido el monedaje, que era el principal indicio de servidumbre), lo cual, sumado al peso de los antiguos Fueros de Ejea (a los cuales, tras la compilación foral de 1247, cabe atribuirles un peso más simbólico que real), allanó el camino al reconocimiento de la hidalguía al común de sus vecinos. Esa reivindicación ya existía a finales del siglo 
XIV, cuando los representantes de Ejea y Sádaba reclamaron sentarse entre los caballeros en las reuniones de las Cortes de Aragón, y en 1405, cuando todos los ejeanos cristianos contribuyeron en un fogaje con la baja nobleza, del mismo modo que trataron de hacer sin éxito los pueblos pirenaicos a los que se había otorgado el mismo Fuero en el pasado (Salvatierra de Escá, Tiermas o Villarreal de la Canal).

Como se ha explicado más arriba, las Cortes de 1372 alegaron contra los hidalgos cincovilleses que su condición no se basaba en el linaje, como requerían los Fueros, por lo que no debían disfrutar de las mismas ventajas jurídicas. De hecho, las viejas diferencias de estatus dentro del vecindario de cada pueblo sobrevivieron a pesar de aquellas concesiones, cuya utilidad se limitaba a una cuestión de prestigio en la relación con las instituciones del reino. La contradicción entre la presunta uniformidad jurídica en torno a la infanzonía y la persistencia de las distinciones se percibe, por ejemplo, en algunos procesos de hidalguía del siglo XVII: «sus vecinos [de Tauste] han gozado y gozan del privilegio de infanzones dentro de la dicha villa y sus términos, a cuya causa no hayan distinción ni diferencia alguna entre los infançones e hijosdalgo a los que no lo son [hombres de condición y pecheros] sino en la notoria reputación y, amás de lo sobredicho, que los que han sido y son infançones de sangre y naturaleza y tenidos y reputados por tales han estado y están insaculados en los officios preheminentes» (Pardo de Vera, 2013: 280).

Tal como Juan Abella aprecia para el caso de Sos (Abella, 2012: 21), las concesiones de hidalguía colectiva cincovillesas facilitaron la fusión de las elites pecheras con los infanzones «antiguos» en un único grupo que tendió a monopolizar el poder local, pero no se tradujeron en una nivelación jurídica de las clases populares..$^{20}$

\section{Burgos, aldeas y masías del Prepirineo}

Más hacia oriente, entre los ríos Arba de Luesia y Gállego, se encuentran varias villas medianas en que la mayoría de sus habitantes eran considerados infanzones a efectos fiscales: Luesia, Orés, Luna, Biel, El Frago, Agüero y Murillo de Gállego. A diferencia de la zona anterior, aquí esas exenciones no se

20 Bastantes concesiones de hidalguía universal en Navarra esconden realidades sociales similares: en la Baja Navarra o el valle de Salazar distinguieron hasta el siglo XVII (cuanto menos) a unos «gentilhombres» $\mathrm{o}$ «hidalgos antiguos», aunque su posición privilegiada generaba a veces contestación entre sus vecinos (Otazu, 1973: 151-189). 
debían a privilegios de hidalguía colectiva, sino a que sus familias fueron progresivamente reconocidas como nobles gracias a procedimientos judiciales que solían afectar a decenas o incluso centenares de personas al mismo tiempo, los cuales se desarrollaron entre 1263 y 1344 y condujeron a que la presencia de pecheros fuese a veces anecdótica. ${ }^{21}$ Los motivos por que el estatuto hidalgo se difundió velozmente en esa pequeña comarca (y no en otras) resultan difíciles de establecer de momento, aunque han de estar relacionados con la abundancia de franquicias personales otorgadas durante los siglos XI y XII, con la introducción tardía de algunas figuras fiscales de la monarquía (Díaz de Durana, 2004: 289) y, quizás, con el contagio de unas localidades a otras.

La hegemonía de la población infanzona se extendía al mosaico de aldeas que cubre las serranías que rodean el actual embalse de La Peña, inmediatamente al norte de los burgos citados en el párrafo anterior. Así, los labradores de Larués, Marcuello, Riglos, Triste o Yeste, entre otros lugares, se afanaron por realizar una salva que les alejaba definitivamente de cualquier forma de servidumbre, en un contexto marcado por la resistencia frente a pequeños señores laicos, tal como han estudiado Elena Lourie (1996) y Carlos Laliena (2012: 466-472). En las grandes honores monásticas de San Juan de la Peña, Santa Cruz de la Serós o San Victorián (curso medio del Gállego, entorno de Jaca, estribaciones de Peña Montañesa), ese mismo proceso de liberación del campesinado no acarreó una situación conflictiva equiparable, ya que las autoridades religiosas tenían pocos recursos para oponerse a los mecanismos usuales de difusión del estatuto privilegiado (matrimonios de herederas labradoras con infanzones segundones, venta de tierras a personas privilegiadas, abandono de explotaciones serviles...) y se resignaron a esa merma constante en sus dominios. ${ }^{22}$

Los infanzones predominaban también en el Viejo Sobrarbe, es decir, en las serranías y altiplanos que se extienden al sur del río Ara y oeste del Cinca. Más concretamente, Guaso, Buil, Olsón o Abizanda eran pueblos de cierta importancia, cuyos habitantes vivían mayoritariamente desperdigados en masías y pequeños caseríos, y donde los hidalgos alcanzaban o superaban la mi-

21 En el siglo XVIII este predominio de los infanzones persistía en muchos de esos pueblos, como se aprecia en los padrones dieciochescos: AHPZ, Real Audiencia, caja 1.869, año 1737: ff. 24r-25v, 68r$68 \mathrm{v}$, etc.

22 Estos mecanismos de difusión de la infanzonía se atestiguan con frecuencia en los mandatos de la Cancillería (ACA, RC, reg. 98, f. 156r; reg. 124, ff. 163v y 205v; reg. 1.059, f. 40v), y también en regiones próximas (Díaz de Durana, 2015: 31-37, 79-81). 
tad de sus fuegos; en Coscojuela de Sobrarbe llegaron a serlo todos. Bastantes familias disfrutaban franquicias anteriores a $1200,{ }^{23}$ pero se debe esperar a los años finales del siglo XIII para que, en el contexto de la ofensiva fiscal de aquellos años, empezasen los pecheros a desertar, tal como el inventario de 1294 apunta para Olsón y Coscojuela y la investigación sobre Buil confirma en 1298 (Bofarull, 1871: 307; Tomás, 2014). En menor medida, este panorama se prolonga en la orilla opuesta del río Cinca (Monclús, Morillo de Monclús o Perarrúa), pero la proporción de infanzones se reduce velozmente conforme nos adentrarnos en el condado de Ribagorza.

\section{Las «repúblicas pastoriles» de los valles del Pirineo}

Los altos valles se configuraron desde el siglo XIII como entidades supralocales que gozaban de una amplia autonomía para la gestión de los recursos ganaderos en que se basaba su economía (Larrea, 2005; Laliena, 2012: 451453). El peso político de esas organizaciones facilitó tanto la uniformidad de los estatutos jurídicos dentro de cada valle, como las enormes divergencias de uno a otro.

Los valles de Sobrarbe (de oeste a este: Broto, Vio, Puértolas, Bielsa y Gistau) eran, junto a las Cinco Villas, el territorio de Aragón donde la proporción de infanzones era más elevada. En el caso de Bielsa y Vio, la fiscalidad de finales del siglo XIII apenas se introdujo debido a la dependencia respecto a señores laicos, pero éstos tampoco disponían más que de una débil autoridad, que dejaba el control del territorio en manos de los organismos comunitarios. Esa situación desdibujó cualquier barrera estatutaria previa y animó al vecindario a reclamar la libertad plena en forma de hidalguía colectiva, la cual se revela en la citada concesión de 1278 a Vio, era implícitamente reconocida por los recaudadores reales en 1405, y se confirmó gracias a los privilegios reales de Alfonso V a Bielsa en 1445 y de Juan II a Vio en 1462. Estas concesiones no siempre fueron acompañadas por la solicitud de numerosas salvas, ya que este trámite era innecesario cuando la condición legal no suscitaba conflictos internos, como sucedía aquí.

23 Los casos son numerosos. Como ejemplo más llamativo, en 1057 García Aznárez de Buil cedió los diezmos de su masía de San Ciprián al monasterio de San Juan de la Peña a cambio de conservar la libertad de que disfrutaban antes de Almanzor y Sancho III de Pamplona (AHN, Clero Regular, carp. $\left.699, \mathrm{n}^{\circ} 13\right)$; algunos descendientes revalidaron su nobleza con una salva de infanzonía otorgada en 1340 (Falcón, 2003: 251). 
Los valles de Puértolas, Broto y Gistau, a diferencia de los anteriores, formaban parte del realengo y se integraron tempranamente en la fiscalidad estatal, lo que supuso un obstáculo para la extensión de la hidalguía. En Puértolas se consiguió por la vía del abandono progresivo de las heredades pecheras, un proceso que estaba avanzado en 1294 y concluido en 1415, y fue acompañado por un goteo de salvas de infanzonía durante la segunda mitad del siglo XIV; gracias a ello, en 1405 había un $90 \%$ de fuegos infanzones y a comienzos del siglo XVI lograron un vago reconocimiento colectivo, mediante una jurisfirma del Justicia de Aragón. En Broto y Gistau fue más complejo: los vecinos de algunas aldeas (Buesa, Oto, Linás de Broto, Serveto o Sin) solicitaron masivamente sus salvas en la primera mitad del siglo XIV y, en algunos casos, todos las consiguieron, de tal manera que los posteriores privilegios de infanzonía colectiva (1360 a Sin, 1408 a Oto) no hicieron más que ratificar esa situación. En otros pueblos, por el contrario, se enquistó la separación entre ambos grupos (Broto o Gistaín), ${ }^{24}$ o se impuso la uniformidad legal dentro de un estatuto de libertad ajeno a la infanzonía, como pasó en Torla gracias a un privilegio de Jaime I en 1258 que suprimía toda servidumbre a cambio de un tributo anual. ${ }^{25}$

Araguiés del Puerto fue el único valle fuera de Sobrarbe en que la hidalguía se extendió a la mayoría de sus habitantes, siguiendo una trayectoria calcada a la de Puértolas: a comienzos del siglo XIV hay quejas de los pecheros ante el rey por la multiplicación de las familias que no pagaban alegando ser infanzonas, las cuales solicitaron y consiguieron progresivamente el reconocimiento de su condición privilegiada; el resultado es que, en el fogaje de 1405, tres cuartas partes de las casas contribuyeron como infanzonas, y el inventario de 1415 consideró que todas lo eran. En otros valles, como Aísa, Canfranc o Tena, existía una minoría hidalga en la mayoría de sus aldeas, pero no hubo un vuelco hacia su universalización; la existencia de graves conflictos entre ambos colectivos desde fechas tempranas (Sallent en 1302, Panticosa en 1344), ${ }^{26}$ motivados por la aspiración de los infanzones a tener un acceso preferente a las áreas de pastos, podrían estar detrás del bloqueo a cualquier estrategia colectiva tendente a la integración.

24 En el valle de Gistau se denunciaron varios impagos de pechas por algunas aldeas donde se habían concedido numerosas salvas. Hacia 1300 las pechas se repartían en tres partes iguales: una correspondía a Gistaín, otra a Plan y otra a las aldeas de Sin, Serveto, Saravillo y Señés, pero desde 1315 a unos pueblos se exigió más para compensar el descenso de los ingresos en otros (ACA, RC, reg. 164, ff. 151v; reg. 573, ff. 189r-189v).

25 ACA, RC, reg. 194, ff. 217v-218r.

26 ACA, RC, reg. 124, ff. 217v-218r; reg. 626, f. 34r. 
En contraste con lo explicado hasta aquí, en los valles de Ansó y Echo las amplias exenciones fiscales, la autonomía en la gestión de sus pastos y la homogeneidad jurídica del vecindario (entendido como la suma de los «casatenientes», lo que excluía a una parte importante de la población), vino de la mano de la ausencia de infanzones. En el primer caso, incluso se detecta una clara hostilidad contra quien trataba de excluirse de la comunidad mediante una hidalguía personal; es el caso del familiar de la Inquisición ansotano Miguel López de Ansó, que logró un privilegio de infanzonía en 1593, tras lo cual recibió graves acusaciones de querer convertirse en «señor», se le ridiculizó públicamente al llamársele «el Barbero» (apodo con que se le conocía antes de ennoblecerse) y sus descendientes acabaron abandonando el valle. ${ }^{27}$ En muchos aspectos, las sociedades ansotana o chesa eran similares a la del colindante valle navarro de Roncal, con la diferencia de que aquí pasaron en bloque a la nobleza gracias a un privilegio real tardío (Otazu, 1973: 176-189; Idoate, 1977: 131-135, 213-219), evidenciando que el camino existente entre la ausencia de infanzones y la infanzonía colectiva era, a veces, corto. Las fracturas estatutarias dentro de una comunidad eran, por el contrario, muy costosas de borrar.

\section{Conclusión}

El estatuto de infanzonía hundía sus raíces en la dicotomía entre «siervos» y «libres» propia de la sociedad pirenaica de los primeros tiempos del feudalismo (Larrea, 2006; Laliena, 2012: 35-119), y su difusión a una parte apreciable del campesinado del norte de Aragón se produjo esencialmente entre 1250 y 1350 , como consecuencia de la suma de múltiples iniciativas individuales y colectivas que perseguían, en última instancia, la exención fiscal.

Más allá de este marco general compartido por todo el territorio analizado, el artículo ha pretendido mostrar que los resultados distaban mucho de ser homogéneos, más allá del manto de uniformidad superficial que genera el uso del vocablo «infanzón»: existían diferencias abismales tanto en la proporción de infanzones como en el nivel socioeconómico de quienes disfrutaban de esa condición. ${ }^{28}$ De este modo, en algunas zonas la difusión de la hidalguía con-

27 AHPZ, Inquisición, caja 88, n. $^{\circ} 8$; caja 92, n. ${ }^{\circ}$ 1. Se conserva también la ejecutoria de infanzonía (Pardo de Vera, 2012: 233-239).

28 Este panorama se aproxima bastante al que se observa en la provincia de Álava, donde existía una elevada proporción de población hidalga desigualmente repartida, y no se produjo la universalización de esa condición propia de las provincias costeras vascas (Díaz de Durana, 2015: 13-50). 
dujo a una cierta igualación legal de los habitantes de una aldea, a la supresión de los remanentes de la servidumbre y, a veces y como consecuencia de lo anterior, a conflictos con las fuerzas sociales que se sustentaban sobre aquella (pequeños señores laicos e instituciones eclesiásticas). En otras partes, por el contrario, sólo los miembros acomodados de la sociedad rural fueron reconocidos como hidalgos, y se esforzaron en reforzar las barreras que les separaban de la población pechera (las distinciones materiales entre ellos eran pequeñas, por lo que las diferencias simbólicas y legales ganaban importancia). Como se ha visto, tampoco faltaban las comunidades que mostraban una aversión declarada contra ellos.

No cabe duda, pues, de que la condición legal del campesinado siguió siendo un elemento crucial en el juego social que se desarrolló en el interior de las comunidades rurales pirenaicas (Freedman, 1991: 220-223). Aquí se han mostrado las divergencias existentes dentro del territorio estudiado y se han sugerido algunas explicaciones generales a las mismas, pero, sin duda, será preciso seguir profundizando en el análisis del interior de esas sociedades rurales para llegar a comprender los orígenes y el significado del estatuto de los infanzones aragoneses.

\section{Referencias bibliográficas}

ABELLA, J. (2006). «Las bases económicas de la elite de los infanzones de Uncastillo en la segunda mitad del siglo XV», Aragón en la Edad Media, 19, 39-51.

- (2008). «Fogaje general del reino de Aragón ordenado en las Cortes de Maella» en G. Navarro (ed.), Acta Curiarum regni Aragonum. Tomo VI. Cortes del reinado de Martín I, Zaragoza, Grupo de Investigación CEMA, 433-672.

- (2012). «La concesión de la infanzonía colectiva a la villa de Sos en 1458», Aragón en la Edad Media, 23, 5-24.

- y SESMA. J. A. (2004). «La población del Reino de Aragón según el fogaje de 1405» en J. A. Sesma y C. Laliena, La población de Aragón en la Edad Media (siglos XIII-XV), Zaragoza, Grupo de Investigación CEMA, 115-164.

BERTHE, M. (1984). Famines et épidémies dans les campagnes navarraises à la fin du Moyen Âge, París, SFIED.

BLANCO, L. (1997). «El precio del poder: la espiral de alienaciones patrimoniales en el reino de Aragón durante el reinado de Pedro IV (1336-1387)», Revista de Historia Jerónimo Zurita, 72, 53-90.

BIELZA, V., CORRAL, J. L., ESCOLANO, S., LALIENA, C., SESMA, J. A., y UBIETO, A. (1986). Estudio histórico-geográfico del Valle de Bielsa (Huesca), Huesca, Instituto de Estudios Altoaragoneses. BOFARULL, M. (1871). Colección de docu- 
mentos inéditos del Archivo General de la Corona de Aragón, XXXIX. Rentas de la Antigua Corona de Aragón, Barcelona, Archivo de la Corona de Aragón.

CONDE, R. (1999). «La Salva de la infanzonía aragonesa: fueros, praxis documental y archivo», Aragón en la Edad Media, 14-15, 313-328.

DÍAZ DE DURANA, J. R. (2004). La otra nobleza. Escuderos e hidalgos sin nombre y sin historia. Hidalgos e hidalguía universal en el País Vasco al final de la Edad Media (1250-1525), Bilbao, Servicio Editorial de la Universidad del País Vasco.

- (2015). «Hidalgos e hidalguía en Álava (siglos XIV al XVI)» en F. J. Goicolea et alii, Honra de hidalgos, yugo de labradores: nuevos textos para el estudio de la sociedad rural alavesa (1332-1521), Bilbao, Servicio Editorial de la Universidad del País Vasco, 13-50.

FALCÓN, I. (2003). Prosopografía de los infanzones de Aragón (1200-1400), Zaragoza, Universidad de Zaragoza.

- (2008). Los infanzones de Aragón en la Edad Media, Zaragoza, Institución Fernando el Católico.

FREEDMAN, P. (1991). The origins of Peasant Servitude in Medieval Catalonia, Cambridge/New York/Melbourne, Cambridge University Press.

GARCÍA DE CORTÁZAR, J. A. (1988). La sociedad rural en la España Medieval, Madrid, Siglo Veintiuno.

IDOATE, F. (1977). La comunidad del valle de Roncal, Pamplona, Diputación Foral de Navarra.

LACARRA, J. M. (1975). «En torno a la propagación de la voz — hidalgo $\square$ » en Homenaje a Don Agustín Millares Carlo, tomo II, Madrid, Caja Insular de Ahorros de Gran Canaria, 43-53.

LALIENA, C. (1996). «Violencia feudal en el desarrollo del estado aragonés: la guerra de Artal de Alagón (1293)» en XV Congreso de Historia de la Corona de Aragón. El poder real de la Corona de Aragón (siglos XIV-XVI), vol. 5, Jaca, Gobierno de Aragón, 151-184.

- (2008). «État, justice et servitude en Aragon au XIVe siècle», Histoire et Sociétés Rurales, 30, 7-30.

- (2012). Siervos medievales de Aragón y Navarra en los siglos XI-XIII, Zaragoza, Prensas Universitarias de Zaragoza.

— , IRANZO, M. T. y MARTÍNEZ, S. (2008). «Actas del proceso de Cortes de Caspe, Alcañiz y Zaragoza (1371-1373» en C. Laliena (ed.), Acta Curiarum regni Aragonum. Tomo III. Cortes del reinado de Pedro IV/2, Zaragoza, Grupo de Investigación CEMA, 277-502.

LAFUENTE, M. (2014). Un reino en armas: la guerra de los dos Pedros en Aragón (1356-1366), Zaragoza, Institución Fernando el Católico.

- y ABELLA, J. (2013). «La baja nobleza aragonesa después del Compromiso de Caspe: movilidad social y estrategias políticas (1412-1436)» en I. Falcón (coord.), 
El Compromiso de Caspe (1412), cambios dinásticos y Constitucionalismo en la Corona de Aragón, Zaragoza, Ibercaja, 432-442.

LAPEÑA, A. I. y AGUDO, M. M. (2003). El Fuero de Ejea de los Caballeros y su difusión. Estudio y transcripción, Zaragoza, Diputación Provincial de Zaragoza/El Justicia de Aragón.

LARREA, J. J. (2005). «Comunidades, puertos, infanzonías. Estado de la cuestión y algunos interrogantes sobre el devenir social y económico del Pirineo navarroaragonés en la Edad Media» en J. Maroto, S. Ramió y E. Ripoll (eds.), Medievalis Historia Pyrenaica II. Congreso Internacional Historia de los Pirineos, Girona, UNED, 47-69.

- (2006). «La condición del campesinado navarro-aragonés entre los siglos IX y XII», En la España medieval, 29, 383-409.

LÓPEZ, M. (2006). «La Edad Media» en Comarca de Sobrarbe, Zaragoza, Gobierno de Aragón, 95-114.

LOURIE, E. (1996). «Seigneurial pressure and the salva de infanzonía: Larués, Marcuello and Yeste (1300-1329)» en XV Congreso de Historia de la Corona de Aragón. El poder real de la Corona de Aragón (siglos XIV-XVI), vol. 5, Jaca, Gobierno de Aragón, 197-208.

MOLINIE-BERTRAND, A. (1974). «Les — hidalgos — dans le royaume de Castille à la fin du XVI ${ }^{\mathrm{e}}$ siècle», Revue d'Histoire Économique et Sociale, 52.1, 48-67.

MONTEMAYOR, J. F. (1665?). Summaria investigación de el origen, y privilegios, de los ricos hombres, o nobles, caballeros infanzones o hijos dalgo, y señores de vasallos de Aragón, y del absoluto poder que en ellos tienen, México.

OTAZU, A. (1973). El «igualitarismo» vasco: mito y realidad, San Sebastián, Txertoa.

PARDO DE VERA, M. (2012). Procesos de infanzonía de la Real Audiencia de Aragón que se conservan en el Archivo Histórico Provincial de Zaragoza, 3 vols., Madrid, Ediciones Hidalguía.

- (2013). Procesos de habilitación de infanzones para acceder a los oficios de la Diputación del Reino de Aragón, Madrid, Ediciones Hidalguía.

SÁNCHEZ, M. (1993). «Sobre la fiscalidad real en el Reino de Aragón durante el primer tercio del siglo XIV: los subsidios para la campaña granadina (13291335)», Revista de Historia Jerónimo Zurita, 67-68, 7-42.

SESMA, J. A. (2004). «Sobre los fogajes generales del reino de Aragón (siglos XIVXV) y su capacidad de reflejar valores demográficos» en J. A. Sesma y C. Laliena, La población de Aragón en la Edad Media (siglos XIII-XV), Zaragoza, Grupo de Investigación CEMA, 23-53.

TOMÁS, G. (2010). «Sociedad de casas y economía ganadera en el Alto Pirineo (Valle de Benasque, siglo XIV», en J. F. Utrilla y G. Navarro (eds.), Espacios de montaña: Las relaciones transpirenaicas en la Edad Media, Zaragoza, Resopyr/ Universidad de Zaragoza, 149-165. 
TOMÁS, G. (2014). «Tanta pobreça que apenas la pueden sofrir: los efectos de la fiscalidad en el Aragón rural de 1300», en J. A. Sesma y C. Laliena (coord.), De la escritura a la historia (Aragón, siglos XIII-XV), Zaragoza, Grupo de Investigación CEMA, 187-201.

VENDRELL, F. (1977). Colección de Documentos Inéditos del Archivo de la Corona de Aragón XLVII. Rentas reales de Aragón de la época de Fernando I (14121416), Madrid-Barcelona, Instituto Universitario de Estudios Medievales. 
Guillermo Tomás Faci

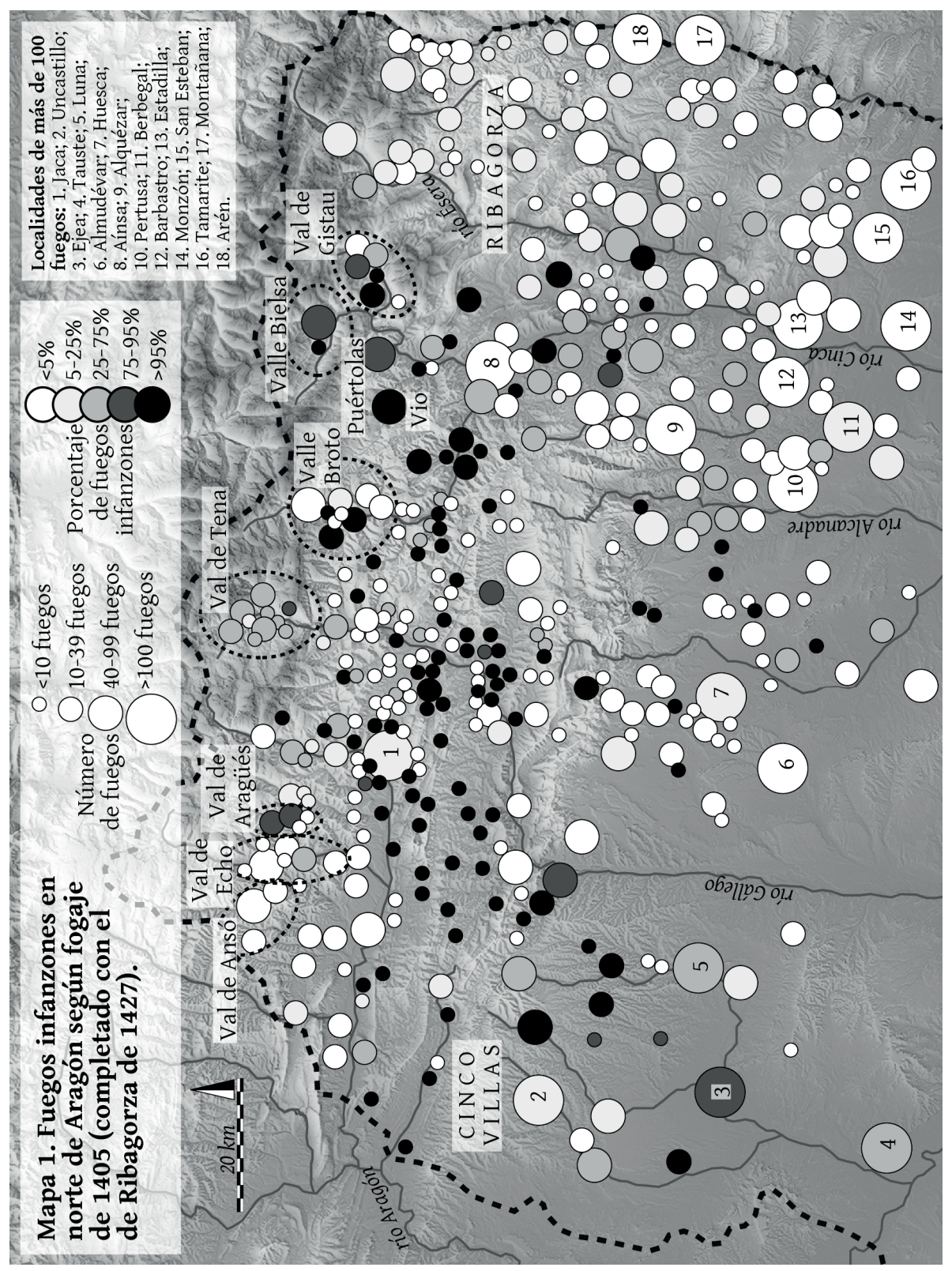

Mapa 1. 


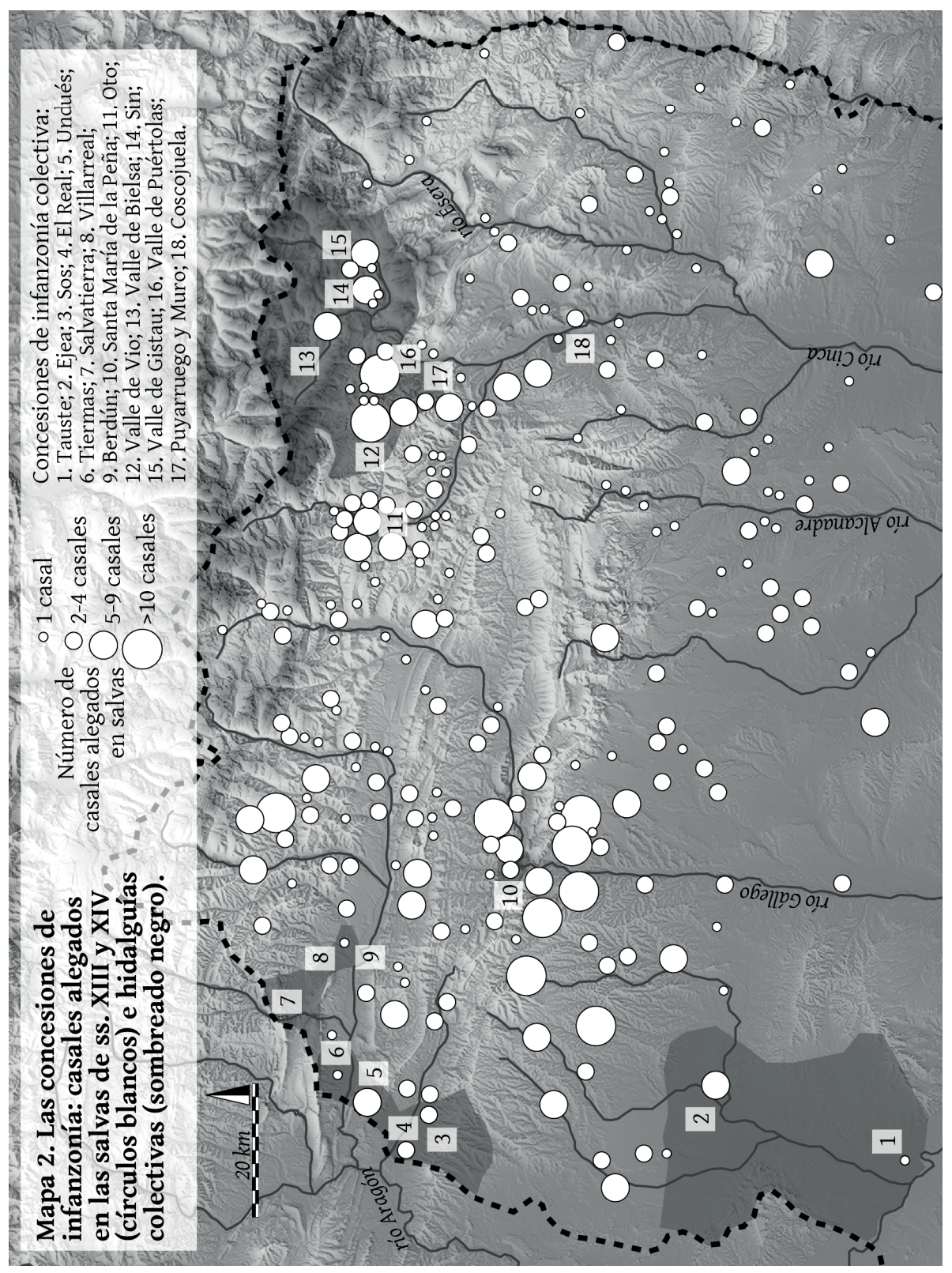

Mapa 2. 